\title{
Developing a strategy for the conservation of performance-based artworks at Tate
}

Louise Lawson (1), Acatia Finbow (2), and Hélia Marçal (3)

(1) Time-Based Media Conservation Manager, Tate, London

(2) Independent Researcher

(3) Andrew W. Mellon Contemporary Art Conservation and Research Fellow, Tate, London.

\begin{abstract}
Over the past two years, Tate's approach to the conservation of performance-based artworks has been evolving. This development has been propelled by the increasing presence of performance and performance-based artworks in Tate's collection and Tate's participation in various research projects. Our current approach considers the altering views in performance studies around the relationship between performance and documentation, and recent considerations around the impact of performance on the systems and structures of the museum. One of the results of the development of our approach is the Strategy for the Documentation and Conservation of Performance. The Strategy takes into account advances in conservation theory around time-based media and performance across departments at Tate, aiming at ensuring the continued activation of performance-based collection works from our collection. This paper explores the process of developing this Strategy, including the defining of terminology and the creation of the three documentation strands which fall under it: the Performance Specification, Activation Report, and the Networks of Interactions map.
\end{abstract}

Keywords (6no.) Tate, Performance, Strategy, Specification, Activation, Network of Interactions

\section{Introduction}

In June 2016 the opening of the Blavatnik Building at Tate Modern signalled a new stage in Tate's life. Five key performances from Tate's collection were performed across a three-week programme called "BMW Tate Live": Amalia Pica Strangers 2008, David Lamelas Time 1970, Roman Ondak Good Feelings in Good Times 2003, Tania Bruguera Tatlin's Whisper \#5 2008 and Tino Seghal This is Propaganda 2002. In 2016 this represented half of the performance-based artworks at Tate's collection and as such provided a unique opportunity to consider these works in action (1). Performance is an art genre that exists somewhere between the visual arts and the performative, which is often characterised by its materialisation through live events but can also incorporate other media and objects. The nature of performance-based artworks, their oscillation between being active and dormant in a way that no other type of art work fully endures, means that it is only when they are performed that we can understand how to properly conserve them (2). The documentation strategy 
used at the time of 'BMW Tate Live' did not account for the artworks variability. Some of these five artworks, on the other hand, lacked documentation produced after the moment of their acquisition, and in the case of Tino Sehgal's work eschewed it entirely. The 'BMW Tate Live' programme thus provided the ideal platform to reassess Tate's conservation processes around performance-based art. Although we were not aware where the process would lead us, we knew what we wanted Tate's approach to the conservation of performance art to be: it was necessary that the process be flexible, adaptable, and - ultimately - useable, to allow the full range of stakeholders within the institution invested in the work to find, use, or retain the relevant information. However, as Tate is also a lending institution any documentation also had to be accessible and understandable to those outside of the museum. As such, our strategy for the preservation of performance had to provide vital production information for the activation of the work outside of Tate's spaces and allow other institutions to, potentially, record the activation of the performance work as it was realized in their own institutional spaces. This would allow a gradual, but substantial, build-up of documents around the performance artwork which would accrue over time and allow the institution to trace the changes over its 'life' (3).

Since 2016, building on knowledge gained regarding these five artworks, and drawing on previous research in the field, the time-based media conservation team have reflected on and reviewed all existing documentation relating to performance artworks. This led to the development of a Strategy for the Documentation and Conservation of Performance (2018). This strategy included agreeing and defining terminology, the development of a Performance Specification, a blank template that can be used to capture written information about a performance-based artworks, the development of an Activation Report, a similar template intended to capture a work in action, and the creation of maps which capture the Networks of Interactions relating to each performance. The paper will explore in detail these tools, considering how and why they were designed and developed, looking at the foundations and motivations that shaped these documents and the implications for the conservation of performance art in the Museum.

\section{Conserving performance art}

Since museums started to collect performance art the conservation of this genre became of utmost importance for institutions, the art market, and scholarly practice alike. While the Strategy for the Documentation and Conservation of Performance does not deal solely with what could be termed 'Performance Art', an arguably highly period-specific term, this genre provides an important starting point for situating the idea of 'performance'(4). The art historian and theorist Jonah Westerman suggests that performance is 'notoriously difficult to wrangle as a category' within the visual arts context (5), while art historian Amelia Jones (6) defines the performative as something that can be 'loosely understood (...) as the reiterative enactment across time of meaning (...) through embodied gestures, language, and/or other modes of signification'. By activating time through movement and 
action, by operating bodies as art materials and, in turn, reconfiguring expectations about the use and value of bodily experience, performance art can be considered one of the most volatile, precarious, and (de)materialised art genres. The ephemerality that has characterised this artistic medium is the ultimate challenge to any ambition to immortalise and collect such works: according to Performance Studies theorist Peggy Phelan, performance artworks cannot be reproduced or fully represented, as they disappear after their materialisation (7). However, approaches stemming largely from Philip Auslander's attitude to documentation (8) have begun to question how far this is the case, and whether performances might exist beyond the singular live moment; documentation may, in fact, be pivotal to the continued existence and future activation - in a multitude of forms - of performancebased artworks. (9)

The conservation of performance art as well as the interrelated genre of Live Art and broader medium of performance itself (10) is quite a recent field of studies within conservation, with few dedicated studies being developed about the theme in either academic or museum contexts (11). Most of the efforts in this direction are either developed in individual projects or stem from the experience of museums collecting performance artworks (12). One of the first steps in the field was undertaken in 2003 when 'The Variable Media Network' proposed Robert Morris' Site, a performance artwork created in 1964, as an example of a performed behaviour (13). 'The Variable Media Network' (VMN, a project funded by the Daniel Langlois Foundation for Art, Science, and Technology) proposes four types of behaviours within contemporary art: contained, installed, interactive, and performed (14). The last two behaviours are particularly crucial for the conservation of performance-based art. According to the authors, performed works are processual artistic manifestations: works where the process is as important as the end result. In this scenario, Robert Morris' Site (1964) is considered a performed work along with Meg Webster's Stick Spiral (1986), which is traditionally considered an installation. Interactive behaviours, on the other hand, imply the visitors' direct or indirect interaction with the work's materials, and researchers from VMN use computer-driven installations as an example.

There are other types of performance artworks that express an interactive behaviour such as Yoko Ono's Cut Piece (1965) or Marina Abramović's Rhythm $O$ (1974). In these, visitors are asked to cut Ono's clothes and to interact with Abramović's naked body, and, as such, these can be considered interactive works in accordance with VMN's definition. Several strategies to preserve variable media works were also presented by Alain Depocas and his team, and included storage, migration, emulation, and reinterpretation (15). Such strategies may be viewed as radical but necessary ruptures with traditional techniques. In the case of performance art, the ways these strategies for preservation are to be applied are still nuanced, as actions cannot be stored, migrated or emulated. The perspective of the 'Variable Media Network' resonates with Jonah Westerman's assertion that '[p]erformance, then, is not some definable object (or anti-object), some discreet entity that fits or cannot fit within 
art's institutions or canons, but an entire network of provocations and fundamental questions about what art is for' (16). This strongly suggests that any performance documentation strategy adopted by the institution needs to reflect the expansive nature of performance and the wide range of works that might be subject to its processes. As will be seen shortly, Tate's strategy has sought to embrace this broad definition of 'performance'.

Over the past twenty years with the rising complexity in the relationship between the museum and the artwork Tate has led the discussions, debates, and new practices emerging around the collection, curation, and conservation of time- and performance-based works of art. From 2003, Tate was involved in the long-term, multi-institution research project 'Matters in Media Art', as a collaborator with the New Art Trust, alongside the Museum of Modern Art (MoMA) and the San Francisco Museum of Modern Art (SFMoMA) (17). In April 2012, the research network 'Collecting the Performative' launched, signalling a focus by the institutions involved from the United Kingdom and Netherlands on the specific issues around the entry of performance-based artworks into museum collections (18). That was a pioneering effort into understanding how to collect and conserve performance art and performance-based art in the museum (19). A key output from this project was The Live List, which details the questions that should be asked every time an institution is thinking about acquiring a performance artwork. An interdisciplinary team is asked to 'agree and understand the basic parameters of the work', including the primary parameters (duration and space, among others), its variability and the amount and nature of the versions an artwork might have, the artworks biography, its context of reference, factors of dependence, and the main challenges facing its activation. (20) The November 2015 conference 'Media in Transition', hosted by Tate and coorganised with the Getty Conservation Institute and the Getty Research Institute, also drew on issues of how cultural institutions approached the 'lives' of complex, time-based works in their collections or in their care (21). The recent AHRC-funded research project at Tate 'Performance at Tate: Collecting, Archiving and Sharing Performance and the Performative' (2014 - 2016) provided an indepth consideration of the history of performance-based and performance-related artworks at Tate (22), which relied primarily on the existence of documentation around historical performance artworks.

Cumulatively, the results of these projects shed light on the difficulties inherent to the process of collecting and conserving performance artworks. In Collecting Performance-Based Art: New Challenges and Shifting Perspectives, for example, Pip Laurenson, Head of Collection Care Research at Tate, and Vivian van Saaze, Director of Maastricht Centre for Arts and Culture, Conservation and Heritage and Assistant Professor at Maastricht University, refer to three main problems that obstruct performance art's incorporation: (1) performance art is traditionally connected to the original event, and the presence of the performer, (2) the museum is usually bounded to material-oriented theories and practices, and (3) these artworks demand a network that is very hard to maintain (23). For these 
authors, maintaining the network needed to support the preservation of these artworks might imply showing specific works with greater frequency, which may not be aligned with Curatorial Programmes, as well as fostering the artworks' social networks that tend to remain scattered and usually difficult to define.

Beyond the VMN and 'Collecting the Performative' (and undoubtedly indebted to them), the literature offers critical remarks about a wide variety of aspects related to the preservation and conservation of performance that informed how the strategy was developed and conceived (24). Amélie Giguère exposes the many ways performance art changes, once it is acquired by museums (25), while Vivian van Saaze when exploring Tino Sehgal's performance works discusses how documentation dispersion in museum departments affects the consolidation of the memory (26). These were important considerations when developing a conservation strategy for performance to ensure that the variable nature of these works was accommodated in practice. Glenn Wharton (27) refers to the acquisition by the Museum of Modern Art of VALIE EXPORT's Abstract Film No. 1 as an act of translation from performance 'to a fixed installation work that could be acquired by the museum'. While 'fixing' an artwork is not the intention of conservation as a wider practice, nor of Tate's performance conservation Strategy specifically, capturing this act of 'translation' or change as instigated by the institution is integral to the Strategy. It does not intend to hide change but instead bring it to the surface and embrace it as part of the life of the artwork within the institution.

\section{Histories of Performance Documentation: Museum, Artistic, and Scholarly Practices (2018), the} introduction to which has been cited here already, also details the relationship between performance art and the institution. This publication presents perspectives from a range of curators, conservators and practitioners with varying relationships to 'performance' and its existence within the museum. It focuses on the processes and production of performance documentation. Its exploration of a range of approaches to the intersection of performance and the museums paved the way for the Strategy to be responsive to existing institutional practices of documentation and to current ontological and philosophical debates about change, disappearance, and activation in contemporary art practices. Within the field of conservation and in the above publication, Gabriella Giannachi (28) also provides new frameworks for understanding the conservation of performance art: first by acknowledging reenactment as a practice of preservation; then by recognising the increasing importance of audience members as content co-producers; and finally, by understanding the artwork as 'a social network of activities'. She adds to this that:

'[The] approaches [portrayed in this book] place the audience at the centre of the process of documentation (...). This suggests that documentation, just like performance, not only should comprise the different phases of these activities, but also that stakeholders from these different phases would reveal, through documentation, diverse aspects of the work' (29). 
This thinking is vital to the Strategy presented in this paper as it draws on a variety of these 'stakeholders' from within the museum. These stakeholders are across diverse departments; each contributes dispersed information which, as Giannachi suggests, 'reveal' aspects of the work which only become clear through the capturing of that department's engagement with the activation of a performance-based artwork. Moreover, Giannachi highlighted two aspects of performance art documentation that have rarely been mentioned before: the importance of the documentation process and the participation of many stakeholders. Giannachi's contribution is one of the first publications to emphasise the need to reflect upon the documentation process itself.

In 2013 Annet Dekker and Vivian van Saaze shared their documentation process and subsequent reflections around the work Extra Dry at NIMk in the Netherlands. Their process considered the specific documentation needs of that work, but also acknowledged that the production of a documentation process as much shaped the future life of the artwork in the institution as the nature of the work itself (30). Hélia Marçal has also contributed to this discussion by reflecting upon how documentation co-constitutes the materialisations of performance artworks, and how, in turn, performance artworks change the nature of conservation (namely through necessitating the reviewing of its methodologies and enhancing the importance of practices of participation) (31). Indeed, while each institution (or, in a sense, each conservator) has its own unique way of documenting complex artworks, there is a strong sense of knowledge sharing and the potential for aspects of these documentation processes to be relevant across a range of artworks and institutions.

From theory to practice: development of the Strategy for the Documentation of Performance Art at TateThe development of the Strategy for the Documentation and Conservation of Performance (2018) was undertaken as a gradual process, which built on varying stages of discussion, research, implementation, and reflection. The process can be described as practice-led, in line with current research done in Conservation Departments at Tate. Indeed, as stated by Lawson and Potter have stated, Tate's 'preservation strategies have evolved continuously...in light of new knowledge gained through research and applied to practice' within the conservation department (32).

Influenced by 'Performance at Tate: Collecting, Archiving and Sharing Performance and the Performative' (33) and the 'BMW Tate Live programme', which enabled practice to be directly linked to research, the Strategy engages with the notion of knowledge sharing through practice in two core ways. Firstly, by directly engaging with inter-departmental practices of documentation and seeking to create a central document as part of the Strategy which can collate these diverse perspectives (from, for example, Curatorial, Learning, and Conservation departments). Secondly, by acknowledging that these documents will not only circulate within Tate, but also between other arts institutions to which the performance works are loaned, and therefore the information contained 
within needs to be complete and clarified enough to be useful to those activating the work beyond Tate.

The first stage of developing a new Strategy for the conservation of performance-based arts was to discuss the issue with those departments most closely associated with the collection, activation, and continuity of the artworks: Conservation and Curatorial. These discussions were crucial in understanding what the needs of these two departments were in terms of facilitating the activation of performance-based artworks in the immediate future. These discussions happened within the departments, as well as between the authors and Assistant Curator (Performance) Isabella Maidment. By establishing what both departments needed and expected from a documentation process contextual information, the closing of knowledge gaps around production, technical information these could be incorporated into the subsequent processes developed.

Having established the institutional needs for the Strategy, the practical generation and implementation of a 'first draft' process of the Performance Specification could be carried out. This was feasible thanks, in part, to a Collaborative Doctoral Award (CDA) attached to the 'Performance at Tate' research project which was in process in 2016. The CDA resulted in a thesis entitled 'The Value of Performance Documentation in the Contemporary Art Museum: A Case Study of Tate' (34). This research traced the history of performance documentation processes and products at Tate, analysing and critiquing existing documentation practices, and speculating on future processes, which fed into the shape of the eventual Specification. Historically, under the broader umbrella of conservation, the time-based media conservation department has used documentation practices to best understand those artworks which are repetitious; to, in some way, seek to capture the intricacies of not only the work, but the activities of production and activation of the work within the museum. For each performance artwork in Tate's collection, the time-based media conservation team has created an artwork record, which forms a body of information from the point of acquisition, from correspondence with the artist, through to all the performance histories since the work entered the collection. This practice has not been overwritten by the process of re-assessing documentation practices around performance artworks, but instead has been incorporated, to ensure that at the heart of the process is a joint consideration of what the artwork is and what it can be.

The Strategy for the Documentation and Conservation of Performance (Fig. 1) has taken on board the issues raised at each stage of development and acknowledges the needs of the various stakeholders involved in activating performance-based artworks at Tate. It has addressed the issue of terminology raised during a key reflective workshop and works towards making each documentation process as easily accessible and usable as possible. The specific development and practice-based research around the Performance Specification was crucial for understanding that performance-based art demanded other tools that could track the changes in artworks and contexts (and how they influence each other), 
and so the Strategy also integrates the Activation Report and map of Networks of Interaction alongside the Performance Specification. The Strategy provides an overarching framework for approaching performance-based art with the intention of conserving its manifestations in order to provide access to present and future generations; how each strand of the Strategy does this is discussed below and illustrated through David Lamelas' performance-based artwork Time.

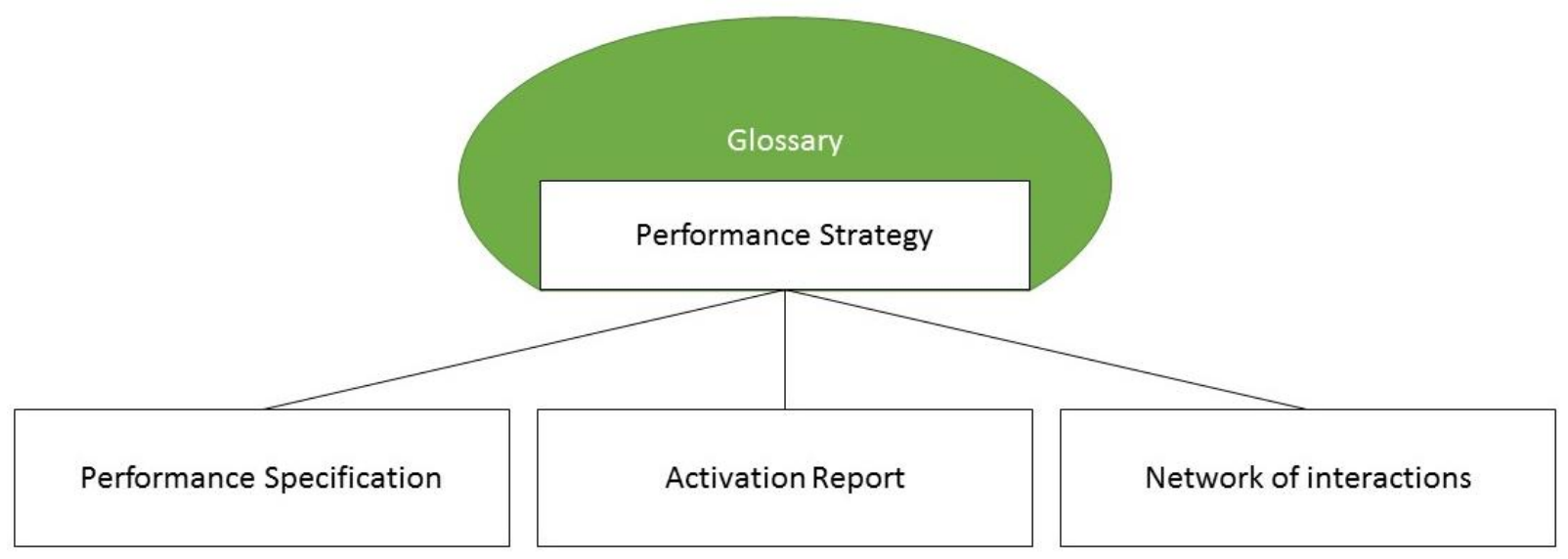

Fig. 1: Diagram illustrating the three branches of the Performance Strategy.

\section{Strategy for the Documentation and Conservation of Performance}

The aim of the Strategy is to retain the live-ness of a performance - the ability to activate it - and, as such, focuses on collecting information around the constant elements of what that performance is, or perhaps needs to be, to exist. Moving away from the idea of capturing the 'original', or first performance, the strategy aims to continuously capture the concept of the artwork. Doing so permits the work to breathe and develop with future activations. A performance cannot be exactly repeated, it will be different each time it is activated and therefore one can expect additions or omissions with each performance. This may involve a conversation with the artist to consider the evolution of the performance over time. Critical to understand with each performance are the constant elements and what is in flux. The aim of the Strategy is to gather sufficient information to activate works, balanced against the need to retain the live-ness and consequent inherent changeability of the work. Failure to strike this balance could result in an overly rigid approach to future activations, risking lessening the impact of the work. It is an interesting juxtaposition to capture suitable levels of information whilst not documenting the work so rigidly it removes the 'soul' of the piece.

The artwork Time, created by the Argentinean artist David Lamelas in 1970 (Fig. 2 and 3) is a good example of a work that could easily be fixated by providing too much information, or misunderstood when providing too little, and so will benefit from reconsideration through the Strategy. Being a 
popular artwork with rather simple instructions Time has been exhibited multiple times both at Tate and in other institutions, which provides us with the information needed to explore the artwork through the three strands of the Strategy. At the same time, by opposition to This is Propaganda, for example, the interactions needed to activate this artwork are simple, which allows for a deep exploration of the Strategy without reducing the case-study. (35) There is also precedent for the documentation of Time visually, as well as through interview with the artist who is forthcoming about the artwork, thus already providing substantial information from which we can explore the constant and flux elements. Finally, Time is commonly activated multiple times during an installation period, which meant that the 2016 activation at Tate provided ample opportunity for first hand observation of the work which could be used to test both the Performance Specification and the Activation Report.

Time starts with several "participants standing side by side along one side of a line that is marked on the floor.' (36) A participant - a member of the public rather than a contracted performer - at one end of the line begins the performance by telling the time to the participant who stands next to them. After waiting sixty seconds, the second participant tells the time to their adjacent performer. When the performance reaches the end of the line, the last participant announces the time in the language they see fit. There are several varying factors around this performance work: the work greatly depends on the number of participants, the time the performance starts, as well as the context of execution that may lead someone to announce the time in a given language. At the moment of acquisition, the artist provided a set of instructions along with a photographic document of the first performance of the work, in which the artist took one photograph per minute, capturing every moment a participant told the time to their adjacent performer. (37) One of the first questions that emerges when facing an artwork such as Time is related to the thresholds of change - i.e. what do we need to capture to activate the artwork? To answer to this question, it is of utmost importance to understand, on the one hand, what 'activation' means and, on the other hand, what the artwork's state is when it is not active.

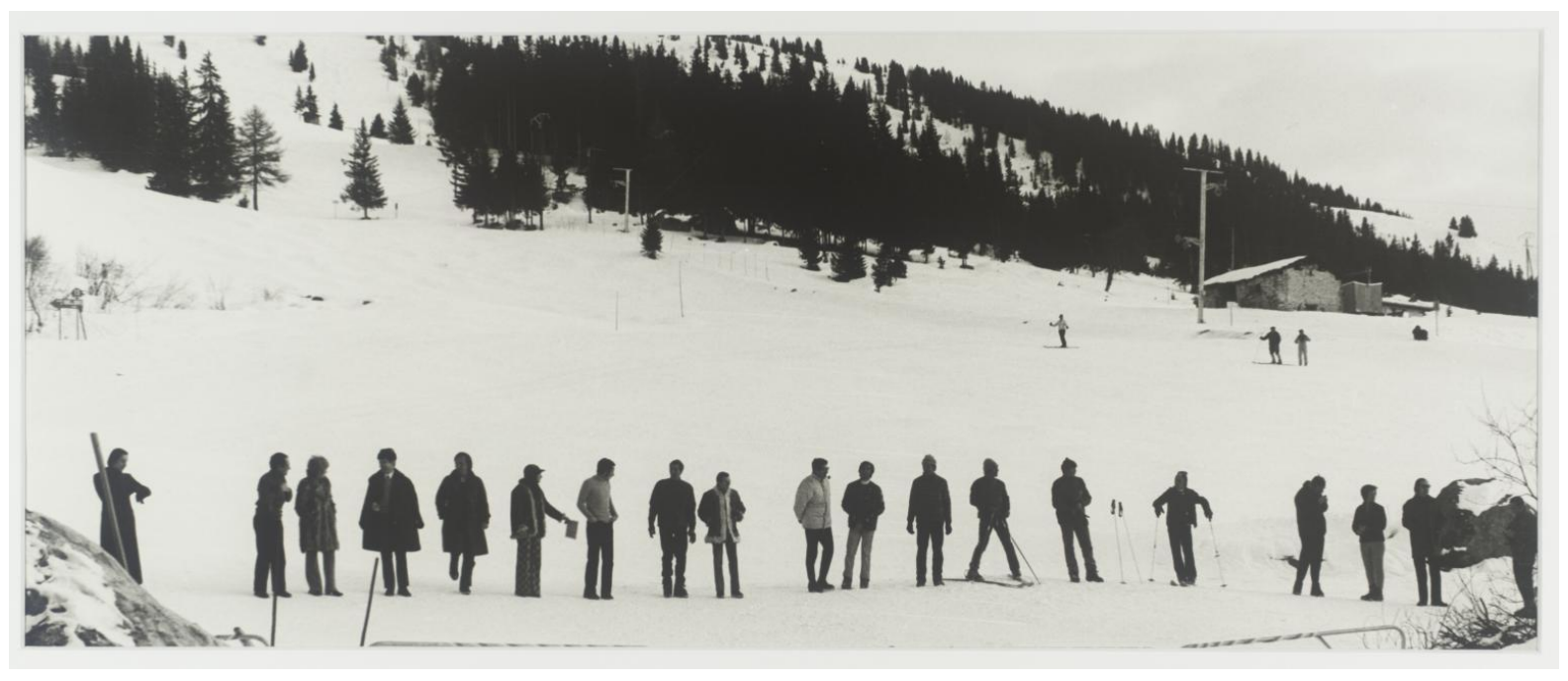


Fig. 2: David Lamelas, Time (1970). This is a photograph of the first performance of the artwork, held in the French Alps in 1970. Lamelas took a photo each moment the performers told the time to each other; it is not clear which moment is portrayed in this document. Photo (C) David Lamelas

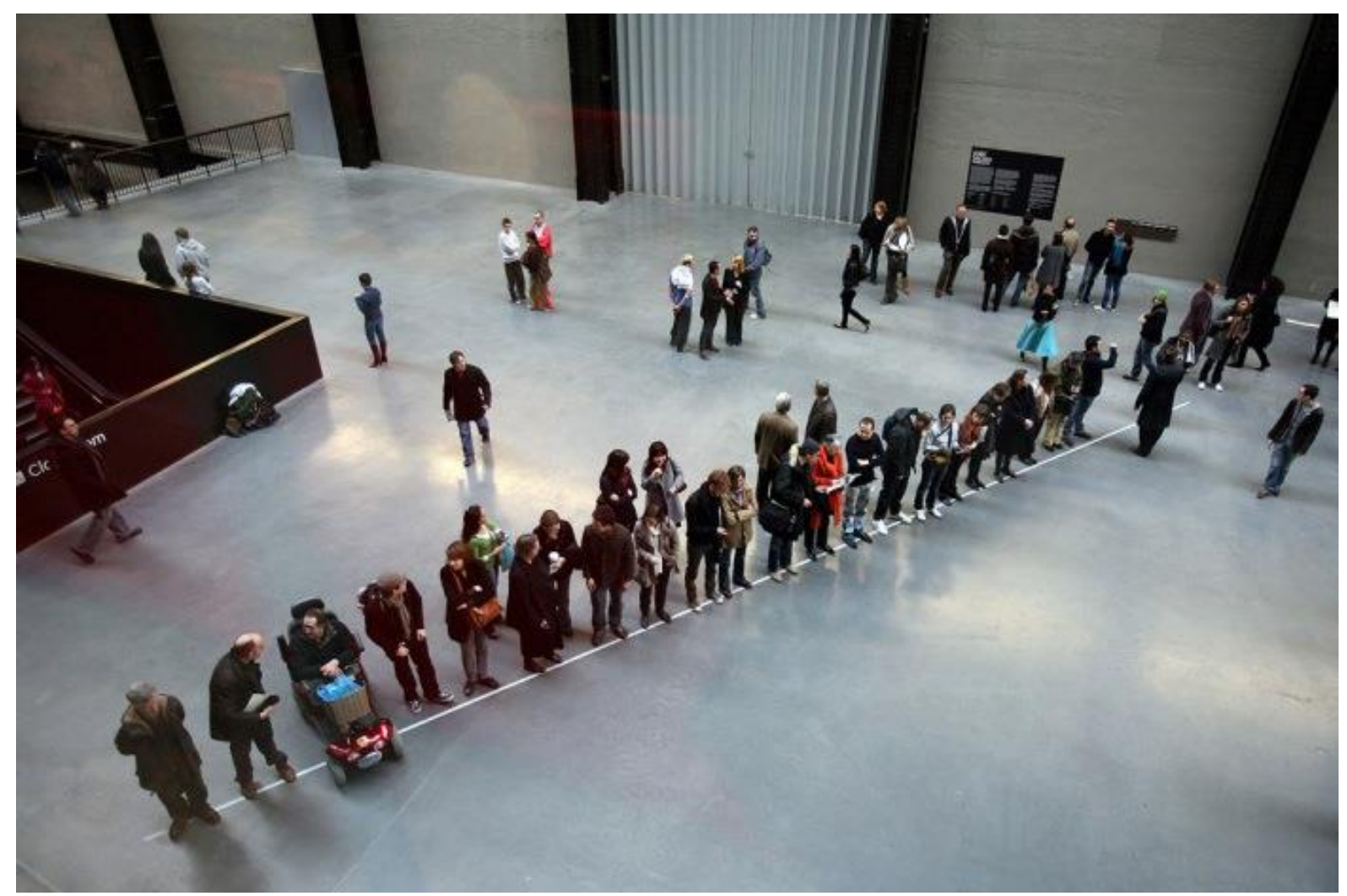

Fig. 3: David Lamelas, Time (1970). Performed in 26-27 January 2008, as part of the curatorial programme UBS Openings: Live - The Living Currency, at Tate Modern. Photo (C) Tate

Indeed, critical to the development of this strategy was the definition of terminology that conservation would use for describing performance artworks. This would ensure consistency and clarity and allows for inter-departmental communication in a transparent way. The reflection on the language used resulted in the creation of a glossary of terms which is outlined at the beginning of the strategy. The glossary is not considered exhaustive but is one that will be expanded as knowledge builds when each performance that enters the collection is activated and installed.

\section{Glossary of Terms:}

Performance: Performance is used to describe the concept of an artworks which has a specificity of performance or performative elements. Performance is described at Tate as; 'artworks that are created through actions performed by the artist or other participants, which may be live or recorded, spontaneous or scripted.' (38) In the context of this Strategy it is considered that performance has a dormant, active and installed presence - existing in all three modes at varying points during its life within the institution. 
Performance-based: Performance-based is used to describe works where performance is the central medium of the work but is not necessarily the only aspect of the expanded artwork. The artwork might have more perennial materialisations (such as a sculpture or an installation) but has elements that can be (or have been) activated as performance. This, crucially, differentiates it from the specificity of both 'Performance Art' and 'Live Art' as genres of artmaking.

Activation: Activation is used to describe the process of preparing the performance for display and presenting it in an active and live manner. Activation is selected over any word using "re:" as this prefix promotes the concept of originality, and instead to adhere to an idea of continuity in the artwork. (39)

Installed State: Installed state is used to describe the performance once it is installed, even if this is for the briefest of moments, but is not yet activated by its performers; it can therefore be seen by visitors to the museum, but it is not yet in an active state.

Dormant State: In the dormant state, the performance-based artwork will have no physical presence in the institution and will not be publicly viewable or accessible. While there may be object components of the artwork preserved and stored by the institution, the performance element is not manifest physically in any way while in this state. It is important to note that this does not constitute a 'disappearance' of the work, but rather a change in visibility and accessibility. (40)

Constant: Constant is used to describe the elements within a performance, as described by the artist, which must be present for the performance to exist.

Flux: Flux is used as the opposite to 'constant', to describe all of the elements that as part of the performance, can change, do change and will change. (41)

Interaction: Given the ramifications of the term in social sciences, in general, and new materialism and STS studies, in particular (42), interaction is particularly hard to define. In the context of the present Strategy, interaction might be considered an action between two entities that results in changes in either of those entities or in their surrounding context. (43)

This choice of terminology shapes the dialogue around performance-based artworks at Tate and is grounded in change and variety. Having established the scope for discussing change within the 
artwork, it then became important to create appropriate documentation practices for addressing that changeability. In the case of Lamelas' Time, it was important to understand (1) what made Lamelas' Time what it is, or, in other words, what is constant in Lamelas' Time, (2) how it changes in each activation, and (3) what factors into those changes. The Performance Specification was intended to be one document which was able to draw together responses to such questions.

\section{Performance Specification}

The Performance Specification consists of a single central written document, containing ten overall headings: Space, Time, Audience/Viewers, Performer, Physical Components, Documentation, Logistics, Conditions, Previous Activations, and Future Activations. Although each work, clearly, had different relationships to these headings, these were all shared facets and elements of the work itself. Each existed within a space and had a relationship with that space, whether deliberate on the part of the artist or consequential of curatorial choices, and information about that relationship might support curatorial decision-making for future performance activations. For each of the ten overarching themes questions were asked that would allow the specificities of the individual artworks to be drawn out, potentially allowing for future comparisons between artworks and their relationships to space, but in the immediate sense identifying information vital to the future activations of the work. The overall intention of this stratification of information across headings is to make the information easily accessible, depending on what the user wants or needs to know about the work. At points, the questions span the boundaries between these headings - 'Where are the viewers located spatially?' for example provides information about both 'Space' and 'Audience'.Each of the brief questions is designed to provide vital information about one facet of a much larger, more complex artwork, but each answer is equally vital in allowing the ability to activate any given artwork. The Specification aims to cross-examine not only the work, but its specific relationship to the museum as the context in which it is produced, and present this information is an accessible, useful way. Although the Specification was created as an instrument to access what the artwork is and can be at the point of acquisition, this model has the potential to be a continuing process of clarification. It was not intended, however, to be used to document continuous changes in the work over time, but neither is it intended to be an 'absolute' document, wherein the information contained within cannot be clarified.

In the case of Lamelas' Time, the final document provides a detailed account of how the artwork should be performed including (1) who should recruit and instruct members of the public, (2) what signals the end of the performance, (3) how frequently the performance should be activated, among other information intended to provide support for those seeking to activate the work. In the case of Time, certain headings had less relevance to the artwork - 'Physical components' for example - and so were less richly completed. The information captured under each heading was drawn from firsthand observation of the work in 2016, discussion with other departments about production 
considerations, and the use of existing documents such as artwork reports from the conservation team. During the testing of the Performance Specification on Time changes to terminology were integrated, as were clarifications in the wording of questions and the highlighting of points of uncertainty or change in the way information was presented. This demonstrates the ability of the Specification to respond to the needs of individual performance-based artworks as these alter over time. A 2018 activation of Time outside of Tate then allowed for deeper reflection on the possibilities and limits of the Specification, particularly as the artist instigated a major change in the frequency of repetition in the work by allowing a single activation to occur across two countries and two time-zones. In this last activation, participants from these two countries were able to follow the performance by their counterparts through live video, synchronising the performance in two time-zones. This activation reiterated the fluidity of the artwork, and the necessity not of fixing it but of capturing and communicating the implications of these changes. This understanding led directly to the undertaking of a second documentation process in the Strategy: the development of the Activation Report as a single, discrete document which could be completed at the point a work is activated, rather than trying to capture the artwork as an expansive, continuing whole.

\section{Activation Report}

The activation report has been developed for use when the artwork is activated within the institution, both at Tate and beyond. As explained in the glossary above, 'activation' is used to highlight the liveness of this state of the work: it refers specifically to the process undertaken to get the work to a position at which it is performed within the space of the museum. The activation report, the format of which is similar to the Performance Specification, captures new information in each instance that the artwork is brought from its dormant state through to its activated state, and also seeks to capture institutional and artistic justification for consequent changes that arise from this activation. As such the Activation Report aims to reflect on the constant and flux aspects of the performance being documented, considering any additions or omissions with each activation. This is a simple narrative to aid the capture of the ongoing histories of the work within Tate. (44)

The activation report is intended to capture the activated artwork at least once during the period in which it is installed, regardless of how long that period might be. It is not intended to capture either the full duration of the installation, or each individual live performance of the work, but rather to consider any artwork-altering changes made from the previous instance of installation and activation. There needs to be a balance in the level of detail captured around change in the work: reporting minute details may risk losing sight of more significant changes while an overly complex process might put users off and equally risks losing vital information. Ultimately, the value of this report is to build a body of knowledge about the performance, to create a rich ongoing history. The report is also supported at Tate by the creation of documentation in other media forms, including photography and 
film, interviews with the artist and participants, and production documents such as contracts. These illustrate points made in the Report while also providing references to return to when exploring change in the work.

In the case of Lamelas' Time, the Activation Report has not been completed as is intended, in synchronicity with the period of production, installation, and activation, but has so far been tested within the time-based media conservation team as a retrospective documentation exercise. This has supported a critique of the Report, in understanding how to capture the decision-making process at Tate by asking for justification of choices made. Using first-hand observation of the 2016 activation during 'BMW: Tate Live' a Report for this installation was partially completed focusing on observable changes from the information captured in the Performance Specification. Although incomplete, the usefulness of the Report became evident in noting changes in the frequency with which the work was activated, capturing the impact of different spaces on the work, and engaging with the artist's subtly altered instructions to participants. Although not yet tested 'in the field', the Activation Report used partially in capturing the 2016 activations of Time has already altered how changes in the artwork, instructions which require clarification, and those elements which remain constant in the work are presented in the Specification, demonstrating the reflexive nature of the Strategy in practice.

As the importance of the Activation Report as a documentation process which can be delegated to museums beyond Tate becomes clear, so does the role of the Network of Interactions (45) in materialising the artworks. Therefore, the final strand of the Strategy, a homonymous mapping document aimed at devising how those Interactions co-constitute the artwork, was developed.

\section{Network of Interactions}

The Network of Interactions is a mapping document that aims to provide an understanding of the networks that exist both internally and externally to Tate and are critical in supporting the institution's ability to activate performance artworks in the collection. As mentioned above, the need for network of interactions was highlighted by Laurenson and van Saaze in 2014, and developed in practice during the process of designing this Strategy. In their seminal article, the authors state:

'The maintenance of the network of relationships necessary to support performance-based artworks $(. .$.$) is best served by the cycle of display, or loan or regular preservation$ management that are already ingrained in the rhythm of the museum. However, there is a disconnect between the frequency of the cycles that exist currently within the museum and the frequency of the refresh cycles that are required to maintain certain types of performancebased artworks' (46). 
In this map, these networks are identified so conservation can understand and assess areas of vulnerability around each artwork and work to address any perceived risk. This is critical for performance artworks which remain dormant in storage until they are activated in the museum, and it also important to assess the ways the artworks can change when they extend beyond the museum walls. Both human and non-human actors are considered in the creation of this network, which is in line with recent studies in the field of Conservation that highlight the role of structures and technology in shaping the artwork's biography. (47) The acknowledgement of the importance of non-human actors, besides allowing for a deeper understanding of their influence, flags possible risks in the structure of care of performance works.

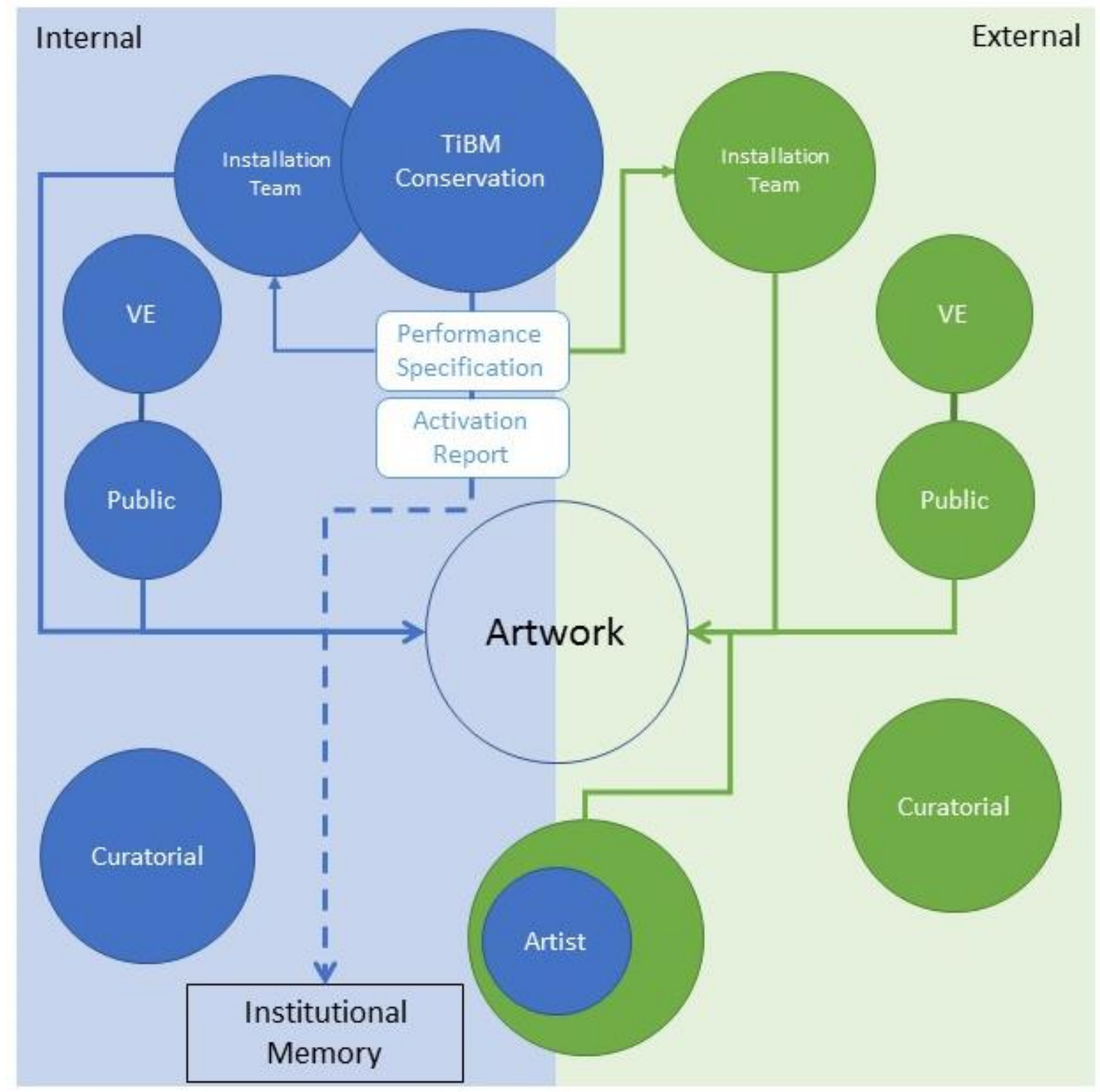

Fig. 4: Scheme illustrating the network of interactions that are involved in the making of David Lamela's Time.

In the case of David Lamelas' Time, the network of interactions can be seen in Figure 4. This scheme highlights the influence of human and non-human actors in the activations of Time that we 
have seen so far. The artist is a focal point in the artwork's network, with their influence changing according to the context (it became more prominent in the 2018 activation when the artist was the instigator of the performance, for example). Indeed, we consider that the artist's voice, either present or absent, as an entity that is always going to accompany the artwork throughout its life.

Other human actors include museum staff (conservators, conservator technicians, AV technicians, curators, visitor experience and education workers, etc.), the context and conditions of the exhibition space, audience members, performers, and the artist. Those actors (both nominally and specifically) might change, as might their influence in the artwork's trajectory. In the case of Lamelas' Time, given that the work is performed by a different group of public participants as well as being observed by the public, there is an already complex positioning of the 'public' in this network, producing an additional layer of complexity. The issue around the 'public' of this performance was yet enhanced during the last activation, when the artwork developed a digital component through the incorporation of live video hoping to achieve some sense of synchronisation between two time-zones. The importance of this and other non-human agents (such as the cell phones from which participants were checking the time), was highlighted in the Network of Interactions along with the interaction paths of those agents with human actors such as members of the installation team and participants, respectively.

Human and non-human actors In the case of future activations outside of Tate, the Network of Interactions is greatly expanded, as it includes the work of Registrars, who typically negotiate the conditions of a loan with a venue, and all associated actors in the museum or gallery to which the artwork is travelling. The vulnerability that might appear in this context is related to the difficulties in developing Activation Reports for activations outside of Tate, where the long-term usefulness of the Report may not be clear to a team having to complete significant short-term work on it. The risk associated with that challenge is also indicated in the Network of Interactions, where extensive contacts with the venue are identified in order to retrieve as much documentation as possible as a necessary strategy to reduce the risk of losing that information. Information management is, after all, at the core of this whole process, which dwells in a practice of preserving Tate's institutional memory about these works. The Network of Interactions also ensues in that practice by underlining that the existence of past documents needs to be critically accounted for when developing new documentation, and how the different versions of this document feed into the institutional memory of these works. And while Visitor Experience (VE), the public, and the team who installs the piece might be directly involved in the materialisation of Time, the time-based media conservation team is also involved in present and future activations as they develop the Performance Specification and Activation Reports.

Overall, the Strategy implies a process in perpetual construction and revision, with multiple moments of feedback that are potentiated by the artwork's activations. In this way, the documentation process is not simply about recording the artwork, the 'live moment' of the performance or the actions 
undertaken by the performers at a given moment but about the full range of the activities undertaken within the scope of the museum to allow the work to be activated repeatedly; this reiterates, again, the points made above around the importance of the completion of the Strategy being a collaborative process across multiple departments in the museum, and with relevant contacts at external museums in the case of future loans. And while the current templates have been developed to answer to Tate's current needs in documenting its performance-based collection artworks, its basic framework is flexible, and alterations can be made to adapt to works with, for example, a stronger sculptural element. As reflections are raised during the use of the documentation process, it can adapt and shift to suit new needs, and incorporate the practices of conservation groups which deal primarily with other non-time-based media. In the meanwhile, the Strategy is being implemented within time-based media conservation and is being continuously tested against performance artworks entering the collection or being proposed for display. This has provided an opportunity to test further and to integrate the strategy into working practice. David Lamelas' work, Time will continue to change and be changed, with the documents from Performance Strategy being, in themselves, a living testimony of the artwork's life and the continuous practices of conservation occurring around it.

\section{Conclusion}

Going through this process of creating a comprehensive Strategy, which encompasses a Performance Specification, Activation Report and map of the Network of Interactions has allowed for a period of focus on the nature of performance and performance-based artworks within Tate as an institution and how best to conserve them. By keeping a practical focus on how the museum can facilitate the continual activation of a performance-based artwork in the present and the future, it has been possible to push the boundaries on what can be done in the museum around the collaborative conservation of performance and performance-based artworks.

This project has allowed a reconsideration of whose responsibility the practices of performance documentation might be. Historically at Tate, departments have developed individual documentation practices which address their perspective on the performance-based artwork. This has often led to a diverse but dispersed body of documentation. The development of the Strategy has been interdepartmental and has sought to respond to the multiple needs of actors within Tate. However the lack of information under certain headings in the Performance Specification and the complexity of the Network of Interactions strongly suggests the need for a period of focused use by a small team at present. As with the implementation of any processes within a large institution, careful consideration has been given to how to communicate the usefulness of the Strategy, to create a shared understanding of specialist terms used in it, and to take on board feedback from those who may, in future, use it. While in the future anyone with access to the Performance Specification and Activation Report may contribute knowledge to them, varying the voices we hear, the practicalities of how this 
might occur within an organisation the size of Tate have not yet been clarified. With further testing, particularly in cases of activations at Tate, it will be possible to observe how those outside of the immediate development team interact with the Strategy and use this to encourage its integration into their own departmental documentation practices. The Strategy was designed to be inter-departmental and to facilitate greater sharing of knowledge, and it will only be fully realised when all those actors with a relationship to performance-based artworks are able to both contribute to and use the documents it encapsulates.

This project has also facilitated a reflection on those theories and practices upon which the Strategy builds and has allowed Tate's conservation practices to continue to move beyond disciplinary boundaries: by reflecting on approaches from conservation theory, art history, and performance studies, we have been able to address and move beyond ontological issues with disciplinary roots. The fixing of artworks, the transformative nature of performance documentation, and the incompatibility of performance as ephemeral with the museum as a site of endurance have become secondary to the practical documentary and conservation needs of performance in the museum. The Strategy recognises performance as a broad and variable practice, which can intersect with other media and which has been utilised by an artist to achieve a specific effect for viewers or, in some cases, participants. This has been reflected in the flexibility and adaptability built into the Performance Specification and the Activation Report, which inform how a performance is activated but are equally informed by the changeable nature of performance-based artworks. While the templates for these may mirror one another across different artworks, they remain flexible enough that the specifics of a singular performance-based artwork can be fully expressed and communicated through them.

Finally, the development of this Strategy has meant that changes within the artwork can be faced head on. This is in part due to the clarification this project necessitated around the language used: which elements are 'constant' and which are in 'flux', what the differences are between the work being 'installed' and being 'activated'. In not only accepting these fluctuations as inherent within the nature of the artwork, but actively seeking to clarify what can be changeable within the parameters of the artwork, the Strategy ensures that those activating the work within the museum do not become paralysed by the potential implications of change within the work, but rather are equipped to make informed decisions which actively facilitate these as they become necessary due to changes in the nature of the artwork, in its relationship to the institution, or in the larger social and political context in which it exists. The Strategy becomes a means of navigating this relationship between institution and artwork assertively and effectively feeding back into the future of that relationship, informing future decision making. 


\section{References}

1. Catherine Wood provides a full list of what she considered to be Tate's performance-based artworks in 2014: Catherine Wood 'Advance of the Broken Arm: Collecting Live Art and the Museum's Changing Game' in Live Forever: Collecting Live Art, ed. T. Calonje (London: Koenig Books, 2015), 123 - 145.

2. Other time-based media works usually have some element of enduring materiality - film, camera equipment, installation elements - which can be 'worked on' during these periods of dormancy, or non-installation. Performance-based artworks may have scripts or instructions, but these are conservation objects themselves rather than parts of the installed or activated artwork, thus putting a different emphasis on their position within the expanded artwork.

3. The term 'career' and 'trajectory' might also be used to consider this prolonged existence of the artwork within the frame of the museum. For more on this, see Vivian van Saaze, Installation Art and the Museum: Presentation and Conservation of Changing Artworks (Amsterdam: Amsterdam University Press, 2013) and Renée van de Vall, Hanna Hölling, Tatja Scholte, and Sanneke Stigter, 'Reflections of a Biographical Approach to Contemporary Art Conservation'. ICOM-CC: 16th Triennial Conference, Lisbon, 19-23 September 2011, ed. Janet Bridgland (Almada: Critério, 2011).

4. Varying authors have considered the rise of performance as a medium within the artistic community. Dematerialisation, as explored by Lucy Lippard and Arthur Danto, is one explanation, whereas Allan Kaprow traces the notions of art as movement in Jackson Pollock's action-painting as a pivotal point. Amelia Jones suggests it stems from the use of the body as an instrument, while RoseLee Goldberg and Claire Bishop both see this bodycentricity as a reaction against the commodification of the artworld. Again, these diverging attitudes attest to the need for the institution to reconsider where performance might be situated within artworks, and what this means for their conservation. See Lucy Lippard, Six Years: The Dematerialization of the Art Object from 1966 to 1972 (London: Studio Vista, 1973); Arthur Danto, After the End of Art: Contemporary Art and the Pale of History (Princeton NJ: Princeton University Press, 1997); Allan Kaprow, 'The Legacy of Jackson Pollock', in Essays on the Blurring of Art and Life (Berkley, CA: University of California Press, 1993[1958]), 1-9; Amelia Jones, 'The Now and the Has Been: Paradoxes of Live Art in History', in Perform, Repeat, Record: Live Art in History, ed. A. Jones and A. Heathfield (Bristol: Intellect, 2012), 11-25; RoseLee Goldberg, Performance Art: From Futurism to the Present, Second and Third Editions, (London: Thames \& Hudson, 2001/2011); Claire Bishop, Artificial Hells: Participatory Art and the Politics of Spectatorship (New York City, NY: Verso Books, 2012).

5. Jonah Westerman, 'Introduction: Practical History, How we do things with performance', in Histories of Performance Documentation: Museum, Artistic, and Scholarly Practices ed. G. Giannachi and J. Westerman (London: Routledge, 2018), 1 - 12, p. 1.

6. Jones, 'The Now and the Has Been: Paradoxes of Live Art in History' 2012, 12.

7. Peggy Phelan, Unmarked: The Politics of Performance (London: Routledge, 1993), 146.

8. See Philip Auslander, 'The Performativity of Performance Documentation', PAJ, 84(3), (2006), 1-10 and Liveness: Performance in a Mediatized Culture, 2nd ed. (London: Routledge, 2008 [1998])

9. The strategies and processes explored in this paper build particularly on theoretical assertions of continuation and activation rather than disappearance and loss, as pursued by Auslander among other authors, such as Christopher Bedford. In a sense, drawing on the words of Christopher Bedford, who characterised the art of performance as an event with recursive 
instances in the minds of its observers, it is possible to see this same recursion in the documentation process. Done in the present, the documentation is built through an archaeology of intentions and other discursive construction which are then materialised in a document. Such forms of mattering, influenced by the ways of seeing the works, have consequences in any future materialities of the work. See Christopher Bedford, 'The Viral Ontology of Performance', in Perform, Repeat, Record: Live Art in History, ed. A. Jones and A. Heathfield (Bristol: Intellect, 2012), 77-88.

10. Typically, 'Performance Art' has been used to refer to those works from the 1970s and 80s where the artist centralises their own body as the material of an often durational artwork, where 'Live Art' is a more contemporary term which can encompass these kinds of works but might also incorporate more complex encounters with 'liveness' which attempt to transcend the notion of 'performing' actions or relationships. Both terms have unclear boundaries, thanks in part to the complexity of incorporating performance as a medium in an artwork.

11. Studies regarding the conservation of performance art (in an overarching idea of conservation as preservation for the future) are usually within one of three lineages, in a region of transdisciplinary confluence: performance studies, media studies, or archival sciences. Conservation, a discipline grounded in art history and (later) museum studies, has recently began to think about this topic. We are aware that conserving performance art first implies a consideration of the ontology of performance, however, is discussion is outside of the scope of this paper. For the purpose of the present discussion, the ontology of performance is here regarded as 'viral' (to use Bedford's notion - see note 9), or rhizomatic. This view has roots in continental philosophy and has recently been revised by new materialism scholars, who argue for a relational ontology. For more on the ontology of performance (within the Conservation field) from the lens of new materialism see Louis van den Hengel, 'Archives of Affect: Performance, Reenactment, and the Becoming of Memory', Materializing Memory in Art and Popular Culture, London/New York: Routledge/Taylor \& Francis 2017, pp. 125-142, or Hélia Marçal, From intangibility to materiality and back again: preserving Portuguese performance art from the 1970s, (unpublished PhD dissertation, Universidade Nova de Lisboa, 2019).

12. An increasing number of museums started to collect around 2010. Published literature shows that, besides Tate, at least MoMA and the Guggenheim, in New York, and the SMK, in Copenhagen, have been collecting performance and developing strategies for their preservation. See Athena Christa Holbrook, 'Second-Generation Huddle. A Communal Approach to Collecting and Conserving Simone Forti's Dance Constructions at The Museum of Modern Art', VDR-Journal Beiträge zum Erhalt von Kunst- und Kulturgut, 1/2018, pp.118; Joanna Phillips, Lauren Hinkson 'New Practices of Collecting and Conserving Live Performance Art at the Guggenheim Museum', VDR-Journal Beiträge zum Erhalt von Kunstund Kulturgut, 1/2018, pp.124; Louise Nicole Cone 'The Variable and Changing Status of Performance Art Relics and Artifacts in Museum Collections', VDR-Journal Beiträge zum Erhalt von Kunst- und Kulturgut, 2/2017, S.106. In this context, it is also relevant to mention the Atelier Boronali, a studio specialised in the conservation, restoration and documentation of performance and art-action, which shows that the relevance of this genre has implied the development of conservation studios dedicated to these artworks. See: http://www.nmnm.mc/index.php?option=com_k2\&view=item\&id=402:atelier-boronali-pourla-preservation-de-l-art-action\&lang=en (accessed 10 December, 2018)

13. Variable Media Network, 'Variable Media Network' http://www.variablemedia.net/e/welcome.html (accessed 16 December, 2016). 
14. Alain Depocas, Jon Ippolito, and Caitlin Jones (eds.), Permanence Through Change: The Variable Media Approach (New York, Montreal: Guggenheim Museum Publications, The Daniel Langlois Foundation for Art, Science, and Technology, 2003). Available at: www.variablemedia.net/pdf/Permanence.pdf (accessed in 31 January, 2016).

15. Depocas et al., Permanence Through Change: The Variable Media Approach (2003).

16. Westerman, 'Introduction: Practical History, How we do things with performance' (2018), 12.

17. Matters in Media Art, 'Guidelines for the Care of Media Artworks', http://mattersinmediaart.org/ (accessed 16 December, 2016)

18. Tate, 'Collecting the Performative: A Research Network Examining Emerging Practice for Collecting and Conserving Performance-based Art', http://www.tate.org.uk/about/projects/collectingperformative (accessed 16 December, 2016).

19. This research network was a cross-disciplinary, cross-institutional, collaborative project, drawing together academics, museum practitioners, and artists from the United Kingdom and the Netherlands through three key meetings. In the final network meeting a group of participants developed 'The Live List', a list of interrogative questions to be asked of a work at its point of entry into the permanent collection of a museum or gallery. See Christiane Berndes, Hendrik Folkerts, Diana Franssen, Adrian Glew, Panda de Haan, Ysbrand Hummelen, Pip Laurenson, Andrea Lissoni, Isabella Maidment, Angela Matyssek, Kate Parsons, Capucine Perrot, Vivian van Saaze, Tatja Scholte, Patricia Smithen, Sanneke Stigter, Paulien 't Hoen, Renée van de Vall, Gaby Wijers, The Live List: What to consider when collecting live works (2017 [2014]). Available at: http://www.tate.org.uk/download/file/fid/107264 (accessed 23 March, 2017).

20. Media In Transition, Tate Modern, 18-20 November 2015, https://www.tate.org.uk/whatson/tate-modern/conference/media-transition (accessed 24 October, 2018).

21. Tate has also received a grant by the Andrew Mellon Foundation in 2018 for the development of the project "Reshaping the Collectible: When Artworks Live in the Museum". This project aims at understanding how variable, uncontained, evolving artworks, such as performance art, can live and prosper in the museum. "Reshaping the Collectible" will build on previous efforts while pursuing new ways of collecting and conserving these artworks. Preliminary results of this project fall, however, beyond the scope of this paper.

22. This project was published online as 'Performance at Tate: Into the Space of Art', https://www.tate.org.uk/research/publications/performance-at-tate (accessed 24 October, 2018).

23. Pip Laurenson and Vivian van Saaze, 'Collecting Performance-Based Art: New Challenges and Shifting Perspectives', in Performativity in the Gallery: Staging Interactive Encounters, ed. O. Remes, L. MacCullock and M. Leino (Oxford: Peter Lang, 2014), 27-41.

24. It is also important to mention that the first conference on the conservation of performance art - "Collecting and Conserving Performance Art" - was held in 2016, having been organised by the German Association of Conservator-Restorers (VDR) and the Kunstmuseum Wolfsburg, Germany. Issues of reperformance, reproduction, relics, and live performance were discussed in two days. Videos available online: https://www.restauratoren.de/collecting-andconserving-performance-art-videos/

25. See Giguère, Amélie, Art Contemporain et Documentation: La Muséalisation d'un corpus de pieces éphémères de type performance (Unpublished $\mathrm{PhD}$ Thesis, Université du Québec à Montréal and Université d'Avignon et des Pays de Vaucluse, 2012) and Giguère, Amélie "Collectionner la performance: un dialogue entre l'artiste et le musée". Muséologies, 7 (1), 
(2014), 169-185. Doi: 10.7202/1026653ar. In her unpublished PhD, Giguère explores how performance art and documents are intertwined in acquisition practices.

26. Vivian van Saaze, 'In the Absence of Documentation: Remembering Tino Sehgal's constructed situations', Performing Documentation in the Conservation of Contemporary Art, Revista de História da Arte, ed. Gunnar Heydenreich, Rita Macedo, and Lucia Matos (Lisboa: Revista de História da Arte, 2015), 55 - 63.

27. See Glenn Wharton, 'Reconfiguring Contemporary Art in the Museum', in Authenticity in Transition: Changing Practices in Contemporary Art Making and Conservation, ed. Erma Hermens and Frances Robertson (London: Archetype Publications, 2016), 27-36, p. 20.

28. Gabriella Giannachi, 'Afterword: the intention of the artist and the point of view of the audience: performance documentation revisited', in Histories of Performance

Documentation: Museum, Artistic, and Scholarly Practices ed. G. Giannachi and J. Westerman (London: Routledge, 2018), 182 - 195.

29. Giannachi, 'Afterword: the intention of the artist and the point of view of the audience: performance documentation revisited', p. 195.

30. Vivian van Saaze and Annet Dekker, 'Surprising uses of a documentation model: On the notion of boundary objects and beyond', International Journal of Performance Arts and Digital Media, 9(1), (2013), 99 - 113.

31. See Hélia Marçal, 'Conservation in the era of participation', Journal of the Institute of Conservation, 40 (2), (2017), 97-104. doi: 10.1080/19455224.2017.1319872, Hélia Marçal and Rita Macedo, 'From the periphery to the center of decision: community engagement and jus-tice in conservation decision-making', ICOM-CC 18th Triennial Conference Preprints, 4 8 September 2017, ed. Janet Bridgland (Paris: International Council of Museums, 2017), and, by the same authors, 'The aim of documentation: micro-decisions of the documentation process of performance-based artworks', ICOM-CC 18th Triennial Conference Preprints, 4-8 September 2017, ed. Janet Bridgland (Paris: International Council of Museums, 2017).

32. See Louise Lawson and Deborah Potter, 'Contemporary art, contemporary issuesconservation at Tate', Journal of the Institute of Conservation, 40 (2), (2017). DOI: 10.1080/19455224.2017.1318079

33. 'Performance at Tate: Into the Space of Art' (2016).

34. Acatia Finbow, The Value of Performance Documentation in the Contemporary Art Museum: A Case Study of Tate, (unpublished PhD dissertation, University of Exeter, 2018).

35. The here described documents are confidential. Templates of the Performance Specification and Activation Report will, however, be available at (pending website).

36. David Lamelas, Time, 1970, https://www.tate.org.uk/art/artworks/lamelas-time-p79205 (accessed 24 October, 2018).

37. David Lamelas, Time, 1970, https://www.tate.org.uk/art/artworks/lamelas-time-p79205 (accessed 24 October, 2018).

38. Art Term: Performance Art, https://www.tate.org.uk/art/art-terms/p/performance-art (accessed 30 October 2018)

39. This term also resonates with some theoretical efforts that consider that performance exists in a state to latency until its materialisation, as explored by van den Hengel, Archives of Affect, 2017.

40. Performance art shares this characteristic with installation art, which only becomes an artwork after installed. See Tatja Scholte, 'Introduction', Inside Installations, Amsterdam University Press, 2012.

41. The idea of identity as a flux was put suggested by various authors (Tina Fiske, Erma Hermens, Pip Laurenson, Vivian van Saaze). This term in relation to artwork's manifestations 
was, however, coined by Brian Castriota. See Castriota 'Authenticity in the Persistence and Recurrence of Contemporary Artworks', June 24-25 2018, NACCA Symposium held at CICS in Cologne, Germany.

42. This term is particularly generative in STS and in new materialist frameworks. The latter often considers intra-actions instead of interactions. For more on this see Karen Barad, Meeting the Universe Halfway, Duke University Press, 2007.

43. The acknowledgement of changes potentiated by various actors across the artwork's life is at the core of this strategy. It was greatly inspired by the biographical approach proposed by van de Vall and her co-authors in 2011. See Van de Vall et al. 'Reflections of a Biographical Approach to Contemporary Art Conservation' (2011).

44. The model for the Activation Report is similar to the one developed by Joanna Phillips at the Guggenheim. It was, however, based in previous reports developed by the Time-Based Media Conservation Team for the installation of time-based media installations. See Joanna Phillips, 'Reporting Iterations: A Documentation Model for Time-Based Media Art', Performing Documentation in the Conservation of Contemporary Art, ed. Gunnar Heydenreich, Rita Macedo, and Lucia Matos (Lisboa: Revista de História da Arte, 2015), 168-79. For Phillips' adaptation of her iteration report to performance art see Joanna Phillips, Lauren Hinkson 'New Practices of Collecting and Conserving Live Performance Art at the Guggenheim Museum', VDR-Journal Beiträge zum Erhalt von Kunst- und Kulturgut, Volume 1/2018, pp.124.

45. Network of interactions was a phrased used by Julie Allinson in her talk 'Starting at the Beginning: creating a City of Culture digital archive' at the British Museums Conference 3rd September 2018, Museums and digital memory: From creation and curation to digital preservation. This was used when referencing function within a digital repository context. Marçal also developed a theory about how performance artworks and conservation processes co-constitute each other through their interactions (or intra-actions, terminology used through a Baradian lens) in her PhD dissertation. See Marçal, From intangibility to materiality and back again, 2019.

46. Laurenson and van Saaze, 'Collecting Performance-Based Art', 2014, 36-37.

47. Several conservation and collection care research initiatives have applied Latour's ActorNetwork Theory and other frameworks within STS (Science and Technology Studies) to the study of contemporary art. See van Saaze, Installation art and the museum, 2013, Fernando Domínguez Rubio, 'Preserving the unpreservable: docile and unruly objects at MoMA', Theory and Society, 43 (6), 2014, p. 617-645, and Yaël Kreplak, 'On thick records and complex artworks. A study of record-keeping practices at the museum', Human Studies, 2018, URL: https://link.springer.com/article/10.1007/s10746-018-9479-3 (accessed $6^{\text {th }}$ December 2018). The role of non-humans is also at the core of new materialism frameworks, as the ones cited in the notes above. 